\title{
Distribution and Number of Grus japonensis (P.L.S. Mull.) and Grus vipio Pall. in the USSR
}

\author{
Yu. V. Shibaev* and N. M. Litvinenko*
}

\begin{abstract}
At present, all the basic habitats of G. japonensis (left tributariers of Zeya River, Bureinsko-Arkharinskaya lowland, a basin of Bolon Lake and Khanka Lake) as well as a number of small colonies and separate pairs were evidently found out. Additional information on Grus japonensis inhabiting the South Kuriles was obtained. Numbers of birds nesting annually in Priamurye ranges approximately from 5-7 to 15 pairs (Smirensky \& Roslyakov 1982). In 198016 pairs were registered in Primorye and in 1981 there were 18-19 successfully nesting pairs. Some pairs of this bird can be assumed to nest on the South Kuriles.

Basins of the Amur and Ussuri Rivers are the real limit of G. vipio distribution on north and east. The nesting grounds of this species established recently are small colonies at the margin of the area. Due to approximate estimates a total number of the reproductive part of population hardly exeeds 20 pairs.

The total number of $G$. japonensis and G. vipio stopping in the lower reaches of Tumannaya River every spring, ranges from several dozens to 150-200 birds of each species.

Further studies on distribution and numbers of both species are needed (searches of unknown nesting grounds, verification of questionable places for nesting, refinement of limits of known nesting grounds, carrying out the regular censuses and marking).
\end{abstract}

\section{Introduction}

During the last decade studies on cranes focused the attention of the Soviet ornithologists. One of the reasons was the conclusion of Convention "On the protection of migrating and endangered birds and of their habitats" signed in 1973 between Japan and Soviet Union.

Within the last years specialists of various institutions realized a number of investigations devoted to biology and modern status of these birds. The studies were carried out under the supervision of the Coordination Committee on the SovietJapanese Convention (Institute of Biology and Pedology, Vladivostok) and Working Group on Cranes established in the Ornithological Committee of the USSR in 1980.

One of the most basic problems of studies was to find out present- day status of crane population and, particularly, to obtain objective information about distribution and abundance of this bird.

This work was complicated by a vast and almost inaccessible territory under study, on the one hand, and sporadic breeding of G. japonensis and G. vipio, on the other.

An objective quantitative estimate of both species in the Soviet Far East will be possible only after detailed examination of their distribution. However, such an order was not always observed in practice.

* Institute of Biology and Pedology, Far Eastern Science Centre, USSR Academy of Sciences, 69022, Vladivostok, 22 USSR. 
The following sources and methods for obtaining information were used in studies of crane distribution: literature materials, questioning of the local people, special observations of the most perspective regions (ground and avia) and materials obtained incidentally in the course of the other studies or by chance.

Estimation of the number was conducted with different accuracy depending upon the extent of study on bird distribution over the area examined:

1. A preliminary estimate (to determine an order of numerals) based, principally, on various indirect and fragmentary information (about a character and condition of bird location, single occurrences, questioning and so on).

2. Absolute crane censuses carried out by various methods. In all cases the aerial observations had very good effects.

A relatively not great extent of some breeding regions of $G$. japonensis and $G$. vipio allowed to carry out the absolute aerial censuses in the Ussurisko-Khankaiskaya plain when the whole area of bird location was covered with a continuous network of parallel transects (Shibaev \& Gluschenko 1982, Shibaev 1982).

The paper is an attempt to evaluate the results obtained recently.

\section{Japanese Crane}

\section{Distribution}

Amuro-Zeiskaya plain: The most northern region of possible nesting of this species is found by Ilyashenko (1982) in the vicinities of Ogoron Lake (the upper reaches of Dep River-left tributary of Zeya River). Here, in summer of 1978 and 1979 birds constantly stayed ( 6 pairs and 1 pair, respectively). In 1980 cranes disappeared due to development of territory. G. japonensis is supposed to nest in the lower reaches of Ushmun River (the right tributary of Orlovka River, a basin of Zeya) (Smirensky \& Roslyakov 1982).

Zeisko-Bureinskaya plain: In 1977 nesting of Japanese Crane was proved for north of the plain in a basin of rivers Ulma, Girbichek, Birma and Tom (With tributaries). All the rivers pertain to a basin of Zeya. These places were little developed, thus being favorable for the crane. Further investigations will undoubtedly reveal the new nesting grounds (Flint \& Smirensky 1977, Smirensky \& Roslyakov 1982).

Bureinsko Arkharinskaya lowland: Within some decades Japanese Cranes were observed over this territory, however, their nesting was proved only in 1965. The nesting ground is located between rivers Bureya and Mutnaya as well as on islands of Amur (Dymin \& Pankin 1975, Pankin \& Neufeldt 1976a, Smirensky 1980). It is of great importance that nesting grounds of cranes are a part of the territory of Khingan State Reserve.

Middle-Amurskaya plain: A basin of Bolon Lake is the most important place of all the well-known regions of G. japonensis location (Roslyakov 1977, Smirensky \& Roslyakov 1982). In 1975 Dr. G. Roslyakov found breeding grounds of this bird in basins of rivers Simmi, Selgon and Kharpi flowing along the vast bog lowlands. These are most remote regions with infrequent visits by people. Single cases of nesting are registered as well in the vicinities of settlement Babstovo (the Jewish 


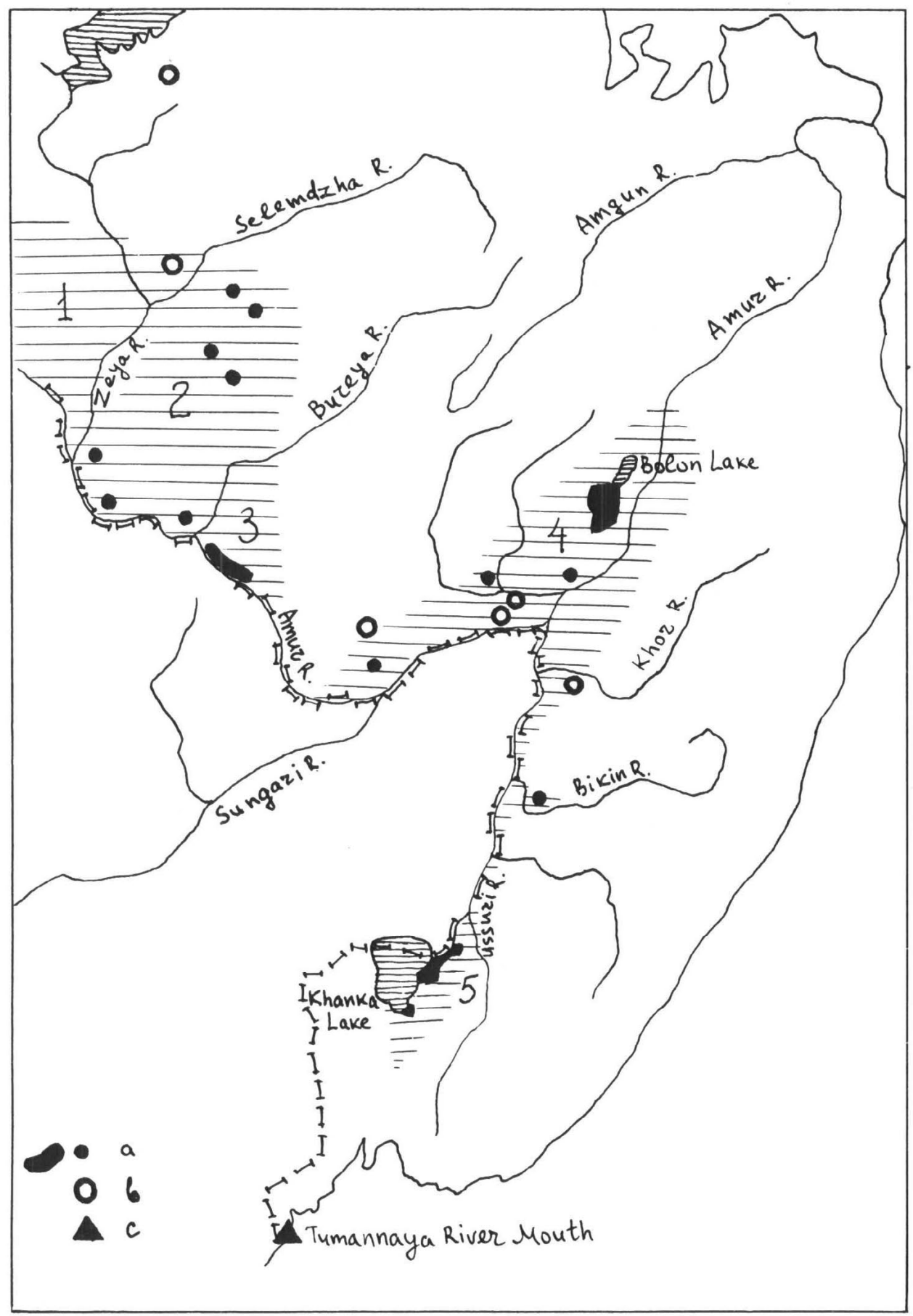

Fig. 1. 
Autonomous Region) and in a basin of Ulika River (basin of Tunguska River, the right tributary of Amur) (Smirensky \& Roslyakov 1982).

Japanese Crane is assumed to nest in a basin of Bidzan River (left tributary of Amur), in flood plain of Amur (higher than Khabarovsk) and lower reaches of Khor River (right tributary of Ussuri) (Shibaev 1982).

Ussuriisko-Khankaiskaya plain: Distribution of G.japonensis in this territory was studied in some detail (Shibaev \& Gluschenko 1982, Shibaev 1982, Shibnev 1982). The nesting grounds are represented mainly as local sites of bogs divided by lands developed for agriculture. At present birds are nesting at the following places: 1) near a mouth of Ilistaya River (basin of Khanka Lake); 2) east side of Khanka; 3) the right bank of Sungach River (left tributary of Ussuri River); 4) lower reaches of Bikin River (right tributary of Ussuri River).

It is safe to say that all the basic breeding grounds of this species are found in Primorye territory and, in particular, on Ussurfiisko-Khankayskaya plain. Only certain nesting pairs will be evidently detected in further survey.

South Kuril Isles: Within the last years (from 1970) the local people and ornithologists (Ostapenko 1981) regularly observed Japanese Crane in breeding time. A family with one juvenile was sighted (questioning information) in the south Kunashir Island (Veslovsky Peninsula) in October 1979. This observation allows to suppose the nesting of some specimens of Japanese Crane in south Kuril Isles.

Extreme South-West Primorye: A plain near the mouth of Tumannaya River situated in the extreme South-West Primorye is the only known place where Japanese Cranes stay for a long time in spring (Shibaev 1975, Litvinenko 1982). This is a marsh plain with sites of reed and numerous mainly brackish reservoirs (lagoons), being the region of limited agricultural activity and sport hunting for the waterfowls. Japanese Cranes appear here in Early March and stay till Late March-Early April feeding on Carassius auratus died in winter. By the start of their flying off White-naped Cranes appear.

In autumn these cranes almost do not stay there. The information is available that Japanese Cranes nest at this place in the past (Shulpin 1936). A reason for a long stopping of birds, possibly, due to forage and climate conditions at the nesting and wintering grounds.

When evaluating an extent of studies on distribution of Japanese Crane in the USSR, as a whole, one can believe that all the main regions for breeding of this species over the USSR territory have been already known now (left tributary of Zeya, Bureinsko-Archarinskaya lowland, basin of Bolon Lake, Khanka Lake). Nevertheless, this work needs to be carried on both in the direction of searches for the unknown nesting grounds up to smallest ones and detailization of limits for the well-known

Fig. 1. Distribution of Grus japonensis in the USSR. (Data by Smirensky \& Roslyakov (1982), Shibnev (1982), Ilyashenko (1982) and our data).

a) places of proved nesting; b) places of supposed nesting; c) place of a long spring stopping.

1: Amuro-Zeiskaya plain, 2: Zeisko-Bureinskaya plain, 3: Bureinsko-Arkharinskaya lowland, 4: Middle-Amurskaya plain, 5: Ussuriisko-Khankaiskaya plain. 
colonies. This provides for the objective information about number of $G$. japonensis.

\section{Numbers}

Priamurye (Amuro-Zeiskaya plain, Zeisko-Bureinskaya plain, BureinskoArkharinskaya lowland, Middle-Amurskaya plain): Censuses and detailed observations similar to censuses in their scope were conducted in this region at two places: over Bureinsko-Arkharinskaya lowland and in a basin of Bolon Lake.

In 1975 over the $162 \mathrm{~km}^{2}$ area of Bureinsko-Arkharinskya lowland, 8 nesting pairs and 8-12 non-breeding birds were registered (Vinter 1977). In the following years number of these birds declined in the region (Smirensky \& Roslyakov 1982). Smirensky \& Roslyakov (1982) consider that in the territory of Middle-Amurskaya plain between Khabarovsk city and Bolon Lake some pairs of G. japonensis up to 25 pairs resided for various years (1975-1980).

In 1980 the aerial survey of the Middle-Amurskaya plain was carried out by one of the authors (Shibaev 1982). Length of the route over the open landscape (meadows, bogs) amounted to $3200 \mathrm{~km}$. $1581 \mathrm{~km}$ of them fell on the territory between Khabarovsk and Bolon. One family ( 2 ad, 2 juv), 4-7 pairs without fledges and a single bird were encountered there. A true number of birds dwelling there appeared to be greater, however, as a whole, figures are close to those given by the mentioned above investigators.

Time and again attempts were undertaken to estimate the number of Japanese Cranes in Priamurye throughout (and in the Soviet Union) involving all the information available up to casual occurences (Smirensky 1980, 1981, Smirensky \& Roslyakov 1982).

Table 1. Status of Japanese Crane population over the Ussuriisko-Khankaiskaya Plain (Primorye) due to results of censuses during the nest period.

\begin{tabular}{|c|c|c|c|}
\hline $\begin{array}{l}\text { Indices characterizing the } \\
\text { population status }\end{array}$ & $\begin{array}{l}\text { Spring } 1978 \\
\text { (terrestrial } \\
\text { census) }\end{array}$ & $\begin{array}{l}25-27 / \text { VIII } \\
1980 \\
\text { aerial census }\end{array}$ & $\begin{array}{c}18-20 / \mathrm{IX} \\
1981 \\
\text { aerial census }\end{array}$ \\
\hline $\begin{array}{l}\text { A total number of registered birds } \\
\text { (in brackets-supposed) }\end{array}$ & $73-78(100)$ & $113(116-130)$ & $\begin{array}{l}91-96 \text { (no complete } \\
\text { census was possible) }\end{array}$ \\
\hline $\begin{array}{l}\text { The number of successfully } \\
\text { nesting pairs }\end{array}$ & - & 16 & $18-19$ \\
\hline $\begin{array}{l}\text { The number of the other pairs, } \\
\text { including ones nesting unsuccessfully }\end{array}$ & - & 25 & $14-15$ \\
\hline $\begin{array}{l}\text { A total number of juveniles (absolute } \\
\text { and } \% \text { of all registered pairs }\end{array}$ & - & $18(15.5 \%)$ & $23-24(25 \%)$ \\
\hline $\begin{array}{l}\text { An average number of juveniles per } \\
\text { I family }\end{array}$ & - & 1.12 & 1.28 \\
\hline $\begin{array}{l}\text { The number of families with broods } \\
\text { of two fledges (absolute and } \\
\% \text { of all the families) }\end{array}$ & - & $2(12.5 \%)$ & $5(28 \%)$ \\
\hline $\begin{array}{l}\text { The number of non-breeding birds } \\
\text { of more than one year age }(\%)^{*}\end{array}$ & 33 & 23 & - \\
\hline
\end{tabular}

* The figure was obtained during the ground observation. 
In the latter paper the authors believe that at present about 5-7 up to 15 pairs nest annually in Priamurye. The figure may increase up to 35-50 pairs under the favourable conditions.

Primorye: Detailed studies on distribution of G. japonensis over the UssuriiskoKhankaiskaya plain allowed to carry out the absolute censuses in this area. The first census was conducted in 1978 (Shibaev \& Gluschenko 1982). An area of crane distribution was covered with a dense network of the terrestrial routes where all the birds encountered were registered. To improve an observation of the locality, the most protruded things i.e. some trees, herdsman houses and shooting-boxes etc. have been used. The number of juveniles failed to be estimated. The census was not strict enough from methodological viewpoint.

The following two censuses were carried out in 1980 and 1981 with helicopter (Shibaev \& Gluschenko 1982, Shibaev 1982). The numbers obtained show objectively the modern situation (Table 1).

Number of Japanese cranes stopping in spring at the lower reaches of Tumannaya River varies approximately from several dozens to 150200 (Shibaev 1975, Litvinenko 1982). Approximity of values is accounted for by a methodological difficulty of census of migrating birds.

\section{White-naped Crane}

\section{Distribution}

At present some places were found in the USSR where this bird was proved to nest.

Zabaikalje: A fact of nesting is confirmed by occurrence of the family with two juveniles in June 22, 1979 in a basin of Agutsa River (left tributary of Onon River). In addition birds in pairs and small groups were frequently observed at time of nesting in the middle stream of Agutsa and in a kettle of the lakes Barun-Torei and Zun-Torei (Vasilchenko 1982). The nesting ground found seems to be a part of the most extensive nesting area which is situated mainly in the adjacent territory of the Mongolian People's Republic covering the extreme north-east (Kucheruk 1977).

Zeisko-Bureinskaya plain: According to questioning information a pair of birds nested in the lower reaches of Zeya River in 1968-69 (Pankin \& Neifeldt 1976).

Bureinsko-Arkharinskaya lowland: Nesting was proved by a number of found nest and hatches (Dymin \& Pankin 1975, Pankin \& Neifeldt 1976, Smirensky 1980). A part of nesting grounds enter the territory of Khingan Reserve.

Middle-Amurskaya plain: Only one nesting ground situated in south-west of the plain is known where a nest was found near the settlement Babstovo in 1978 (Smirensky \& Smirenskaya 1980).

Ussuriisko-Khankaiskaya plain: Nesting of $G$. vipio in a basin of Khanka lake is known from the time of Przhevalsky N. M. (1870). Recently, a fact of nesting of White-naped Cranes on Khanka was confirmed by Yu. Gluschenko and by us (Gluschenko 1981). At present, these birds irregularly nest in few numbers on the north-east side of the lake. For some years single families were observed by us in the middle stream of Sungach River. 
In spite of our detailed survey of this region (terrestrial and aerial) these birds were found nowhere during the last years. It is clear that all nesting grounds of G. vipio are recognised in the Soviet part Ussuriisko-Khankaiskaya plain.

\section{Numbers}

Smirensky \& Roslyakov (1982) consider that not more than 10 breeding pairs inhabit Priamurye. In 1978 4-5 pairs nested in Primorye (Gluschenko 1981). Even including birds breeding in Zabaikalye (Vasilchenko 1982), the total number of the reproductive part of $G$. vipio population in the USSR is unlikely to exceed 20 pairs. It must be remembered that this figure is not a result of strict census, it is an approximate value. White-naped Cranes do not nest in Primorye some years.

The number of birds migrating in spring in the extreme southwest Primorye in the lower reaches of Tumannaya River ranges from several dozens to one and a half-two hundred (Shibaev 1975). A part of them, migrating over south Primorye, flew away to the North and appeared to settle in the extensive Amuro-Sungariiskaya lowland.

Thus, at present the main nesting grounds of $G$. japonensis in the USSR were found out and attempts were undertaken to estimate the numbers of this bird. An order of numerals for cranes dwelling in Priamurye was established and more precise information about numbers in Primorye was obtained.

One can suppose that annually 25-30 pairs of Japanese cranes nest successfully in the USSR during the last years.

To judge from the quantitative estimations obtained, the Prinkhankayskaya plain is of particular concern as a habitat of $G$. japonensis since this place is apparently occupied by not less than a half of all birds of this species in the USSR. Results of censuses (Table 1) indicate that Khanka population of Japanese Crane is in a state of the active growth. Conserving this position for number of future years a great increase of its population would be expected.

In the nearest future the Soviet ornithologists are faced with the following:

1. to continue and complete studies on disribution of $G$. japonensis and, firstly, in Priamurye;

2. to extend the calculations to receive objective quantitative informations;

3. to continue and extend marking of Japanese Crane with colour rings to find out seasonal distribution of some populations*.

In continuation of such works, a simultaneous census of $G$. japonensis throughout its whole range should be conducted.

Distribution and number of $G$. vipio in the USSR are less studied than that of $G$. japonensis. Hence, it is necessary to continue and extend these studies considering the fact that numerosity of $G$. vipio is markedly lower.

\section{References}

Dymin, V. A. \& Pankin, N. S. 1975. Nesting and migration of storks Ciconiidae and cranes Gruidae in the

* In summer 1981 and 1982 we have marked 15 juveniles of $G$. japonensis on Khanka. The leg yellow marks kindly offered by Dr. G. Archibald have been used. 
Upper Priamurye. In Ornithological Studies in the Soviet Far East. pp. 263-267. Vladivostok: Far East Science Center Acad. of Sci. of USSR.

Efremov, V. F. \& Pankin, N. S. 1977. On distribution of some birds in the Upper Priamurye. In Fauna of the Far East. pp. 25-53. Blagoveschensk., ser. 2.

Flint, V. E. \& Smirensky, S. M. 1977. New data on distribution of G. japonensis (Müll.) and Ciconia boyciana Swinh. Abstracts of the VII All-Union Ornith. Conf. p. 251, Naukova Dumka, Kiev.

Gluschenko, Yu. N. 1981. Nesting birds of Khanka lowland. In Rare birds of the Far East. pp. 25-33. Vladivostok: Far East Sci. Center Acad. Sci. of USSR.

Ilyashenko, V. Yu. 1982. On cranes in a basin of Upper Zeya (Amur Region). In Cranes of the East Asia. Far East Sci Center of Sci of USSR, Vladivostok.

Kucheruk, V. V. 1977. New data on distribution of Grus vipio. Abstracts of the VII All-Union Ornith. Conf. pp. 224-225. Kiev: Naukova Dumka.

Litvinenko, N. M. 1982. On the necessary protection of Tumannaya River Mouth as a stopping-place of cranes. In Cranes of the East Asia. pp. 92-97. Far East Sci. Center Acad. of Sci. of USSR, Vladivostok.

Ostapenko, V. A. 1980. On the avifauna of Kunashir Is. (South Kuril Isles). In Ornithology. pp. 156-157. Moskow State University, Moscow.

Pankin, N. S. \& Neifeldt, I. A. 1976a. Grus japonensis in Amur Region. In Rare Endanged and Little Known Birds of the USSR. Proceedings of the Okskiy State Preserve. pp. 86-92.

Pankin, N. S. \& Neifeldt, I. A. 1976b. Grus vipio in Amur Region. Ibid. pp. 117-120.

Przhevalsky, N. M. 1870. Tour round Ussuri Territory in 1867-1869.

Roslyakov, G. E. 1977. About rare birds of the Low Priamurye. Abstracts of the VII All-Union Ornith. Conf. pp. 241-243. Kiev: Naukova Dumka.

Shibaev, Yu. V. 1982. On distribution and number of $G$. japonensis in the eastern area. In Cranes of the East Asia. pp. 18-26. Vladivostok: Far East Center Acad. of Sci. of USSR.

Shibaev, Yu. V. \& Gluschenko Yu. N. 1982. Modern status and problems of conservation of Japanese Crane on Khanka Plain. Ibid. pp. 35-43.

Shibnev, Yu. B. 1982. Japanese Crane nests on Bikin river (Primorye). Ibid. pp. 98-99.

Shulpin, L. M. 1936. Game and Carnivorous Birds of Primorye. Vladivostok. 360 p.

Smirensky, S. M. 1980. Range and quantity of G. japonensis and G. vipio. In Ornithology. No. 15. pp. 26-35. Moscow State University, Moscow.

Smirensky, S. M. \& Smirenskaya, E. M. 1980. Some rare and little studied birds of the Jewish Autonomous Region. Ibid. pp. 205-206.

Smirensky, S. M. \& Roslyakov, G. E. 1982. Status of breeding grounds of cranes in Priamurye. In Cranes of East Asia. pp. 12-17. Vladivostok: Far East Sci. Center Acad. of Sci. of USSR.

Vasilchenko, A. A. 1982. Cranes of Transbaikalia. Ibid. pp. 101-103.

Vinter, S. V. 1977. Nesting of G. japonensis in the central Priamurye. Bull of Moscow Society of Naturalists, ser. Biol. 82: 39-53. 